\title{
Peak ground motion predictions with empirical site factors using Taiwan Strong Motion Network recordings
}

\author{
Jen-Kuang Chung \\ Center for General Education, Chien Hsin University of Science and Technology, No. 229 Jianxing Rd., Zhongli City, Taiwan 320
}

(Received August 7, 2012; Revised January 25, 2013; Accepted March 19, 2013; Online published October 9, 2013)

\begin{abstract}
A stochastic method called the random vibration theory (Boore, 1983) has been used to estimate the peak ground motions caused by shallow moderate-to-large earthquakes in the Taiwan area. Adopting Brune's $\omega$-square source spectrum, attenuation models for PGA and PGV were derived from path-dependent parameters which were empirically modeled from about one thousand accelerograms recorded at reference sites mostly located in a mountain area and which have been recognized as rock sites without soil amplification. Consequently, the predicted horizontal peak ground motions at the reference sites, are generally comparable to these observed. A total number of 11,915 accelerograms recorded from 735 free-field stations of the Taiwan Strong Motion Network (TSMN) were used to estimate the site factors by taking the motions from the predictive models as references. Results from soil sites reveal site amplification factors of approximately $2.0 \sim 3.5$ for PGA and about $1.3 \sim 2.6$ for PGV. Finally, as a result of amplitude corrections with those empirical site factors, about $75 \%$ of analyzed earthquakes are well constrained in ground motion predictions, having average misfits ranging from 0.30 to 0.50. In addition, two simple indices, $R_{0.57}$ and $R_{0.38}$, are proposed in this study to evaluate the validity of intensity map prediction for public information reports. The average percentages of qualified stations for peak acceleration residuals less than $R_{0.57}$ and $R_{0.38}$ can reach $75 \%$ and 54\%, respectively, for most earthquakes. Such a performance would be good enough to produce a faithful intensity map for a moderate scenario event in the Taiwan region.
\end{abstract}

Key words: Peak ground motion, site factor, stochastic method, attenuation, intensity.

\section{Introduction}

Local geological conditions at specific sites are possibly the most critical factors in analyzing ground motions. One famous case is the widespread damage to buildings from strong ground motion following a particular pattern after the $1999 M_{\mathrm{w}}$ 7.6 Chi-Chi earthquake in Taiwan (Shin et al., 2000; Shin and Teng, 2001). As shown in $\sim 400$ accelerograms recorded at free-field stations (Lee et al., 1999), stronger ground shaking appears clearly at regions well beyond the vicinity of the Chelungpu fault: for example, the Taipei metropolitan area, the Ilan plain, and some southwestern coastal regions. By comparing the response spectra of observed ground motions during this earthquake with predictions from commonly used ground motion prediction equations, Boore (2001) found that the observed motions differed from predicted by factors larger than expected from an earthquake-to-earthquake variation. The explanation could probably be attributed to specific site and propagation effects. Unless there is a clear understanding of the profile of the geological strata near the free surface, and seismograms recorded at ideal hard-rock sites are collected, it is generally difficult to isolate the site response from complicated overall effects that could mostly origi-

Copyright (C) The Society of Geomagnetism and Earth, Planetary and Space Sciences (SGEPSS); The Seismological Society of Japan; The Volcanological Society of Japan; The Geodetic Society of Japan; The Japanese Society for Planetary Sciences; TERRAPUB.

doi:10.5047/eps.2013.03.012 nate from the heterogeneity of the structure along the propagation path, and the variation of seismic energy radiated from the source. Besides carrying out geotectonic investigations over the study area, in practice a forward simulation of ground motion response seems to be an efficient method without a foreknowledge of every individual effect on the motion. However, from this perspective, the estimated ground motion can only be applied to generic sites located in a specific region and may fail to agree with observations to a large extent.

Following the Chi-Chi event, earthquake risk prevention in Taiwan remains an important issue. To achieve this goal, ground motion prediction is strategically used to establish an adequate building code for earthquake engineering and hazard assessment, based on the possible peak ground motion at a given distance from a large scenario earthquake. To find a link between the ground shaking and seismic damage, the peak ground acceleration (PGA) and peak ground velocity $(\mathrm{PGV})$ induced by seismic waves in a frequency range of $0.5 \sim 10 \mathrm{~Hz}$ are generally simulated by statistical methods instead of theoretical or numerical modeling, since threedimensional heterogeneities and non-uniform fault rupturing make seismograms more complex. Based on a great number of available recordings, regression techniques have been usually used to obtain prediction equations for peak ground motions in the Taiwan area (e.g. Tsai and Bolt, 1983; Tsai et al., 1987; Ni and Chiu, 1991). In such results, the behavior in attenuation of peak amplitude with 
distance may have a poor correlation with local site effects because the data used at that time was limited to a specific condition. In those studies, the common characters of the data used have revealed a lack of generalization of analyzed earthquakes and the localization of the recording area, without strictly considering the site categories. Even with a particular concern about the local-site response of metropolitan regions in some improved studies (e.g., Tan and Loh, 1996; Shin, 1998; Liu, 1999), the prediction equations still dominate over the regression of peak ground motions for the entire Taiwan area. Basically, this implies that the averaging effects on the source pattern and seismic attenuation along the propagation path seem to be an essential drawback for a more precise prediction of ground motion for any scenario event.

Liu and Tsai (2005) derived new ground motion prediction equations for crustal earthquakes in Taiwan using a traditional regression method. The earthquake magnitude and hypocentral distance are the only two parameters during regressions for deriving their attenuation relationships. However, another popular approach to predicting the ground motion requires a source model and a predictive relationship which allows the estimation of a specific ground motion parameter as a function of magnitude, distance, source parameters, and frequency. The predictive relationship is characterized by a geometric spreading function, a frequencydependent crustal $Q$ function, and a function describing the effective duration of the ground motion. Following the approaches described in the papers of Raoof et al. (1999) and Malagnini et al. (2000), the regional attenuation of seismic waves in Taiwan is firstly investigated in this study. The predictive relationships here were built up by a great number of strong motion data collected by the Taiwan Strong Motion Network (TSMN) operated by the Central Weather Bureau (CWB) under the Taiwan Strong Motion Instrumentation Program (Shin, 1993). Essentially, the advantage of their method over the classical regression analysis is to take into account the duration parameter as a function of frequency and distance, which is more effective in structural engineering applications.

A stochastic method called the random vibration theory was then used to estimate the peak motions of a set of random time histories. Finally, comparing the predicted peak motions with the observations, the generalized local site effect can be examined to correct the peak motions at every single station for a realistic scenario earthquake.

\section{Procedure to Derive Attenuation Relationship}

Following the statements in Raoof et al. (1999), Malagnini et al. (2000), and Malagnini and Herrmann (2000), the spectral ordinate of the ground motion is represented in a general form for a predictive relationship as follows:

$$
\begin{aligned}
\log a(r, f)= & \log E\left(r_{\text {ref }}, f\right)+\log P\left(r, r_{\text {ref }}, f\right) \\
& +\log S(f),
\end{aligned}
$$

where $a(r, f)$ is the peak amplitude of the ground acceleration recorded at the hypocentral distance $r$ and bandpass filtered at a central frequency $f . E\left(r_{\text {ref }}, f\right)$ represents the seismic source term scaled to a fixed reference distance $r_{\text {ref. }} P\left(r, r_{\text {ref }}, f\right)$ describes the crustal attenuation in the region, and $S(f)$ is the local site term. The instrument factor is mostly eliminated when the motions are recorded by seismometers having the same response in the frequency range of interest. To obtain an empirical estimate of the path term in Eq. (1), a coda normalization technique (Aki, 1980; Frankel et al., 1990) can be used to eliminate the source and site terms by taking the ratio of the peak amplitude carried by $S$ or $L_{\mathrm{g}}$ waves in filtered time histories to the root-mean-square ( $r m s$ ) amplitude of the stable seismic coda. The coda-normalized amplitude can be written in the form:

$$
\begin{aligned}
\log a_{\mathrm{cn}}(r, f)= & \log P\left(r, r_{\mathrm{ref}}, f\right) \\
& -\log P_{\text {coda }}\left(r, r_{\text {ref }}, f\right),
\end{aligned}
$$

where

$$
a_{\mathrm{cn}}(r, f)=a(r, f) / a_{\mathrm{coda}}(r, f) .
$$

According to Parseval's theorem, in practice, a proper time window within the coda waves is chosen for calculating the rms amplitude. A better criterion indicates a length of window longer than the reciprocal of the lowest frequency of interest. The preliminary estimates of the empirical path term account for the intrinsic and scattering attenuation, geometrical spreading, and the general increase of duration with distance due to wave propagation and scattering at each hypocentral distance for each frequency. Based on the results of the coda normalization method, therefore, the $Q$ quality factor model of the $S / L_{\mathrm{g}}$ waves propagating through the crust will be inverted by giving a proper geometrical spreading model.

\section{Strong Ground Motion Data}

A large number of strong ground motion data are needed in regression analyses for the propagation behavior of seismic waves over a wide region of interest. The TSMN currently consists of over seven hundred free-field digital accelerographs, mainly deployed over nine metropolitan areas in Taiwan. Each strong motion station is equipped with a three-component force-balanced accelerometer with a 16bit resolution and a 96-db dynamic range. Most of these stations are located on the sedimentary ground of elementary schools. Deriving the attenuation term from a predictive relationship, such as Eq. (1), has the inherent advantage of minimizing the variability of the site response, which can be approached by analyzing seismograms recorded at rock sites. Taking this into account, a total of 65 strong motion stations denoted in Fig. 1, recognized as class B (rock sites) based on geologic and geomorphologic data (Lee et al., 2001; Lee and Tsai, 2008) were selected as reference stations. The mean shear-wave velocities in the upper $30 \mathrm{~m}$ $\left(V_{S 30}\right)$ at these rock sites, which were mostly located in the Central Range and the northern mountain area, could be summarized to be in the range $760 \sim 1,500 \mathrm{~m} / \mathrm{s}$ from the $P$ $S$ logging profiles. Strictly speaking, these sites cannot be considered as reference stations which, by definition, must have a nearly flat transfer function with an amplitude of one. Steidl et al. (1996) have shown that surface-rock sites can have a site response of their own. However, such a concern 


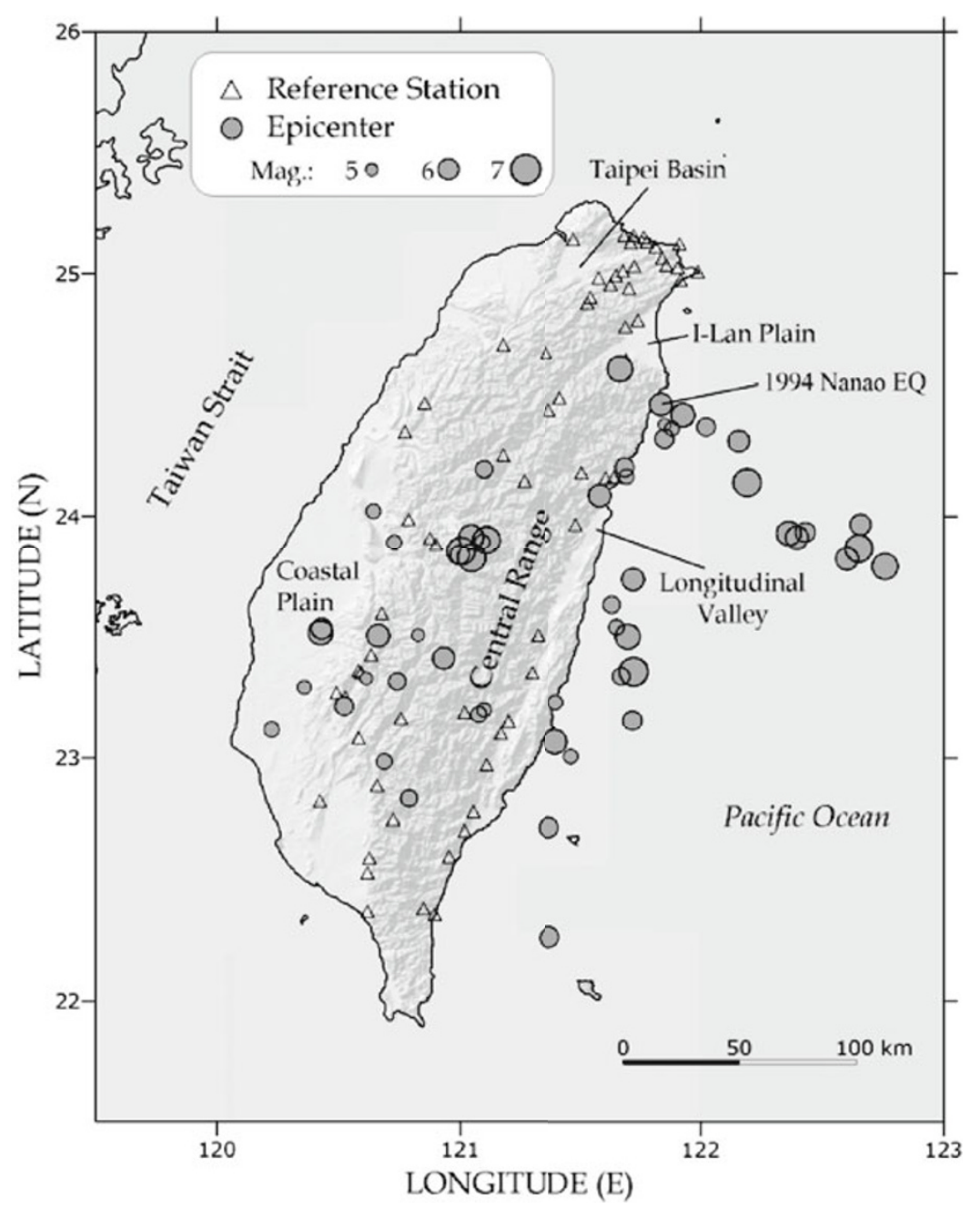

Fig. 1. Distribution of 54 epicenters (denoted as circles) of shallow earthquakes and 65 selected reference stations (denoted as triangles) analyzed in this study. The diameter of each circle is proportional to the local magnitude.

is not of relevance in this study, because the site response due to near-surface weathering of the rock can be almost extracted through a correction factor in taking the ratio of the in-situ measurement to the prediction.

In the period from 1993 to 2006, there were 54 earthquakes, as given in Table 1 and shown in Fig. 1, selected from the seismic database of the CWB with the criteria of a local magnitude ranging from 5.0 to 7.0 and a focal depth shallower than $40 \mathrm{~km}$, which could be associated with seismic hazards. It is clear that the distribution of most earthquakes which occurred in eastern Taiwan corresponds with the boundary between the Philippine Sea plate and the mainland China continental shelf which belongs to the Eurasian plate. The 1999 Chi-Chi mainshock was removed from the list due to its complicated behavior induced from a $\sim 100 \mathrm{~km}$ extensive rupture along the Chelungpu fault. Figure 2 demonstrates the distribution pattern of the hypocentral distance versus magnitude for the 1,002 threecomponent accelerograms collected. Ground motions at reference stations for the selected earthquakes were basically recorded within a source-receiver distance of $200 \mathrm{~km}$. All the acceleration waveforms (e.g. an example is shown in Fig. 3) were carefully inspected on the computer screen to ensure the quality of the data satisfying the criteria of not having abnormal spikes, electrical noise and multiple signals in the windows of interest. Eventually, a total of 2,004 horizontal-acceleration time histories were gathered as the dataset for deriving the crustal attenuation and strong motion duration in this study.

\section{Characterization of Propagation in the Crust}

Each accelerogram was first narrow-bandpass filtered around each of the following frequencies: 0.2, 0.25, 0.33, $0.4,0.5,1.0,2.0,3.0,4.0$, and $5.0 \mathrm{~Hz}$. The bandpass filter used here is defined by a 10th-order Gaussian function in the frequency domain. The peak amplitude of each filtered time history, carried by direct $S$ or $L_{\mathrm{g}}$ waves windowed at a length of $5 \sim 10 \mathrm{~s}$ depending both on distance and magnitude, was then picked out. It has been pointed out that the general form of coda can be established after $2 \sim 3$ times the $S$-wave travel time from the origin time of an event (Rautian and Khalturin, 1978; Spudich and Bostwick, 1987). Due to a shortening of the record length caused by the preset of the trigger mode, the length of the time window, expediently starting $20 \mathrm{~s}$ after the onset of an $S$-wave, for calculating the rms amplitude of coda waves, was set to be $10 \mathrm{~s}$ in this study.

Using the coda normalization technique described in the 
Table 1. List of used earthquakes selected from the CWB database.

\begin{tabular}{|c|c|c|c|c|c|c|c|c|}
\hline \multirow[t]{2}{*}{ No. } & \multicolumn{2}{|c|}{ Origin Time (UT) } & \multicolumn{2}{|c|}{ Epicenter } & \multirow{2}{*}{$\begin{array}{c}\text { Depth } \\
(\mathrm{km})\end{array}$} & \multirow{2}{*}{$\begin{array}{l}\text { Magnitude } \\
\left(M_{\mathrm{L}}\right)\end{array}$} & \multirow{2}{*}{$\begin{array}{c}\text { Distance* }^{*} \\
(\mathrm{~km})\end{array}$} & \multirow{2}{*}{$\begin{array}{c}\text { Record } \\
\text { No. }\end{array}$} \\
\hline & & & Lon. $\left({ }^{\circ} \mathrm{E}\right)$ & Lat. $\left({ }^{\circ} \mathrm{N}\right)$ & & & & \\
\hline 1 & $1993 / 12 / 15$ & $21: 49$ & 120.524 & 23.213 & 12.50 & 5.70 & 65.1 & 143 \\
\hline 2 & $1994 / 03 / 28$ & $8: 11$ & 120.687 & 22.985 & 14.37 & 5.41 & 59.6 & 84 \\
\hline 3 & $1994 / 05 / 24$ & 4:00 & 122.603 & 23.827 & 4.45 & 6.17 & 175.9 & 164 \\
\hline 4 & $1994 / 06 / 05$ & 1:09 & 121.838 & 24.462 & 5.30 & 6.20 & 100.6 & 220 \\
\hline 5 & $1994 / 10 / 05$ & $1: 13$ & 121.720 & 23.156 & 31.28 & 5.83 & 161.2 & 203 \\
\hline 6 & $1995 / 02 / 23$ & $5: 19$ & 121.687 & 24.204 & 21.69 & 5.77 & 101.4 & 293 \\
\hline 7 & $1995 / 04 / 03$ & $11: 54$ & 122.432 & 23.935 & 14.55 & 5.88 & 144.8 & 137 \\
\hline 8 & $1995 / 05 / 27$ & $18: 11$ & 121.465 & 23.008 & 19.73 & 5.26 & 105.5 & 141 \\
\hline 9 & $1995 / 06 / 25$ & $6: 59$ & 121.669 & 24.606 & 39.88 & 6.50 & 103.6 & 324 \\
\hline 10 & $1995 / 07 / 07$ & 3:04 & 121.090 & 23.893 & 13.07 & 5.30 & 77.2 & 162 \\
\hline 11 & $1995 / 07 / 14$ & $16: 52$ & 121.851 & 24.320 & 8.79 & 5.80 & 91.8 & 195 \\
\hline 12 & $1995 / 10 / 31$ & $22: 27$ & 120.359 & 23.291 & 10.65 & 5.19 & 45.9 & 122 \\
\hline 13 & $1996 / 03 / 05$ & $14: 52$ & 122.362 & 23.930 & 6.00 & 6.40 & 142.3 & 222 \\
\hline 14 & $1996 / 11 / 26$ & $8: 22$ & 121.695 & 24.164 & 26.18 & 5.35 & 91.8 & 191 \\
\hline 15 & $1998 / 07 / 17$ & $4: 51$ & 120.662 & 23.503 & 2.80 & 6.20 & 77.4 & 246 \\
\hline 16 & $1998 / 11 / 17$ & $22: 27$ & 120.790 & 22.832 & 16.49 & 5.51 & 60.8 & 150 \\
\hline 17 & $1999 / 09 / 20$ & $17: 57$ & 121.044 & 23.912 & 7.68 & 6.44 & 93.6 & 345 \\
\hline 18 & $1999 / 09 / 22$ & $0: 14$ & 121.047 & 23.826 & 15.59 & 6.80 & 106.8 & 385 \\
\hline 19 & $1999 / 09 / 25$ & $23: 52$ & 121.002 & 23.854 & 12.06 & 6.80 & 100.8 & 375 \\
\hline 20 & $1999 / 10 / 22$ & $2: 18$ & 120.426 & 23.515 & 16.64 & 6.40 & 101.0 & 340 \\
\hline 21 & $1999 / 10 / 22$ & $3: 10$ & 120.431 & 23.533 & 16.74 & 6.00 & 83.7 & 269 \\
\hline 22 & $1999 / 11 / 01$ & $17: 53$ & 121.725 & 23.358 & 33.53 & 6.90 & 143.4 & 407 \\
\hline 23 & $1999 / 11 / 17$ & $7: 35$ & 120.643 & 24.019 & 9.55 & 5.29 & 53.2 & 110 \\
\hline 24 & $2000 / 02 / 15$ & $21: 33$ & 120.740 & 23.316 & 14.71 & 5.59 & 66.5 & 214 \\
\hline 25 & $2000 / 05 / 17$ & $3: 25$ & 121.098 & 24.193 & 9.74 & 5.59 & 70.1 & 121 \\
\hline 26 & $2000 / 06 / 10$ & $18: 23$ & 121.109 & 23.901 & 16.21 & 6.70 & 103.7 & 432 \\
\hline 27 & $2000 / 07 / 28$ & $20: 28$ & 120.933 & 23.411 & 7.35 & 6.10 & 91.2 & 263 \\
\hline 28 & $2000 / 08 / 23$ & $0: 49$ & 121.635 & 23.636 & 27.48 & 5.57 & 99.8 & 154 \\
\hline 29 & $2000 / 09 / 10$ & $8: 54$ & 121.584 & 24.085 & 17.74 & 6.20 & 87.2 & 228 \\
\hline 30 & $2000 / 12 / 10$ & $19: 30$ & 120.226 & 23.116 & 12.02 & 5.35 & 69.3 & 165 \\
\hline 31 & $2000 / 12 / 29$ & $18: 03$ & 121.884 & 24.361 & 6.96 & 5.26 & 53.5 & 85 \\
\hline 32 & $2001 / 03 / 01$ & $16: 37$ & 120.997 & 23.838 & 10.93 & 5.80 & 75.8 & 206 \\
\hline 33 & $2001 / 06 / 14$ & $2: 35$ & 121.928 & 24.419 & 17.29 & 6.30 & 101.3 & 284 \\
\hline 34 & $2001 / 06 / 19$ & $5: 16$ & 121.077 & 23.177 & 6.58 & 5.41 & 68.9 & 116 \\
\hline 35 & $2001 / 06 / 19$ & $5: 43$ & 121.098 & 23.197 & 11.70 & 5.22 & 82.9 & 141 \\
\hline 36 & $2001 / 12 / 18$ & 4:03 & 122.652 & 23.867 & 12.00 & 6.70 & 169.5 & 238 \\
\hline 37 & $2002 / 02 / 12$ & $3: 27$ & 121.723 & 23.741 & 29.98 & 6.20 & 123.1 & 385 \\
\hline 38 & $2002 / 03 / 31$ & $6: 52$ & 122.191 & 24.140 & 13.81 & 6.80 & 143.6 & 421 \\
\hline 39 & $2002 / 05 / 28$ & $16: 45$ & 122.397 & 23.913 & 15.23 & 6.20 & 142.8 & 173 \\
\hline 40 & $2002 / 08 / 28$ & $17: 05$ & 121.372 & 22.261 & 12.03 & 6.03 & 90.7 & 66 \\
\hline 41 & $2002 / 09 / 06$ & 11:02 & 120.729 & 23.890 & 28.82 & 5.30 & 64.3 & 156 \\
\hline 42 & $2002 / 09 / 30$ & $8: 35$ & 120.614 & 23.328 & 8.12 & 5.04 & 62.2 & 174 \\
\hline 43 & $2003 / 06 / 09$ & $1: 52$ & 122.023 & 24.370 & 23.22 & 5.72 & 109.7 & 332 \\
\hline 44 & $2003 / 06 / 09$ & $5: 08$ & 121.851 & 24.380 & 2.36 & 5.03 & 57.6 & 115 \\
\hline 45 & $2003 / 06 / 10$ & $8: 40$ & 121.699 & 23.504 & 32.31 & 6.48 & 136.6 & 494 \\
\hline 46 & $2003 / 06 / 16$ & $18: 33$ & 121.654 & 23.542 & 28.26 & 5.38 & 104.2 & 231 \\
\hline 47 & $2003 / 12 / 10$ & $4: 38$ & 121.398 & 23.067 & 17.73 & 6.42 & 131.5 & 480 \\
\hline 48 & $2004 / 05 / 19$ & 7:04 & 121.370 & 22.714 & 27.08 & 6.03 & 117.4 & 284 \\
\hline 49 & $2004 / 11 / 08$ & $15: 54$ & 122.760 & 23.795 & 10.00 & 6.58 & 181.1 & 237 \\
\hline 50 & $2004 / 11 / 11$ & $2: 16$ & 122.158 & 24.312 & 27.26 & 6.09 & 97.3 & 132 \\
\hline 51 & $2005 / 01 / 20$ & $7: 47$ & 120.826 & 23.505 & 19.16 & 5.04 & 66.3 & 160 \\
\hline 52 & $2005 / 02 / 18$ & $20: 18$ & 121.674 & 23.340 & 15.28 & 5.60 & 95.5 & 149 \\
\hline 53 & $2005 / 09 / 26$ & $18: 50$ & 121.401 & 23.232 & 21.34 & 5.29 & 57.3 & 70 \\
\hline 54 & $2006 / 07 / 28$ & $7: 40$ & 122.658 & 23.966 & 27.97 & 6.02 & 152.7 & 104 \\
\hline
\end{tabular}

${ }^{*}$ The distance is an arithmetic mean of epicentral distances for triggered strong-motion stations of TSMN. 


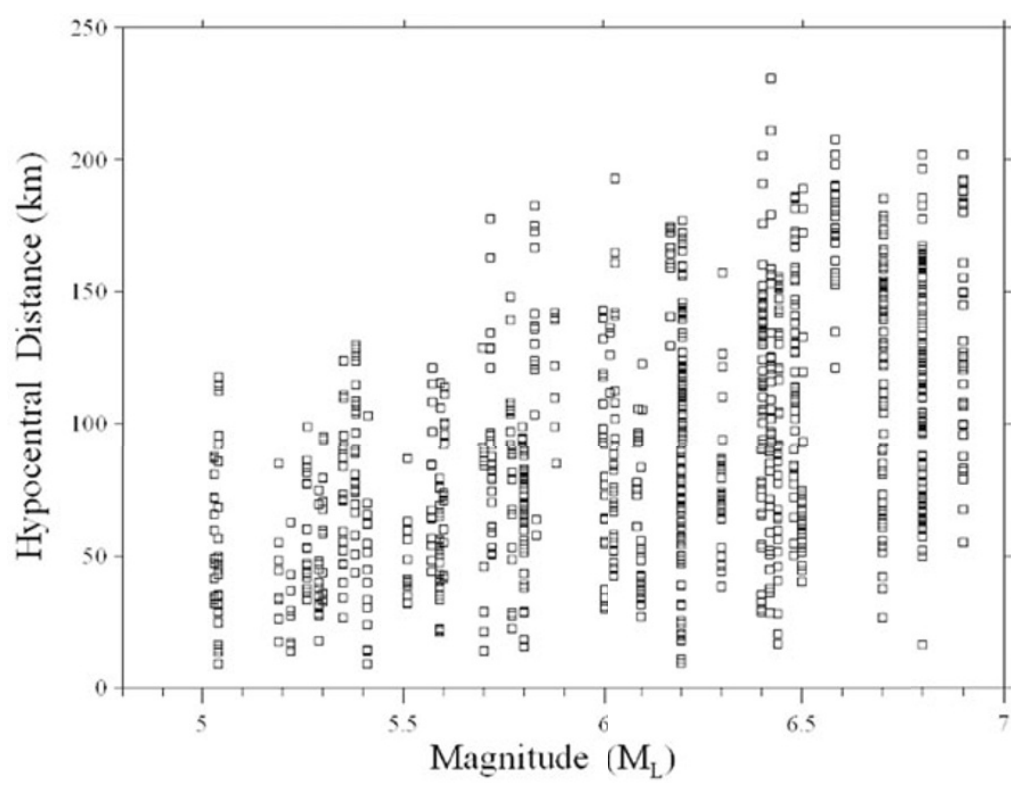

Fig. 2. Pattern of local magnitude versus hypocentral distance for the analyzed accelerograms recorded at the reference stations.
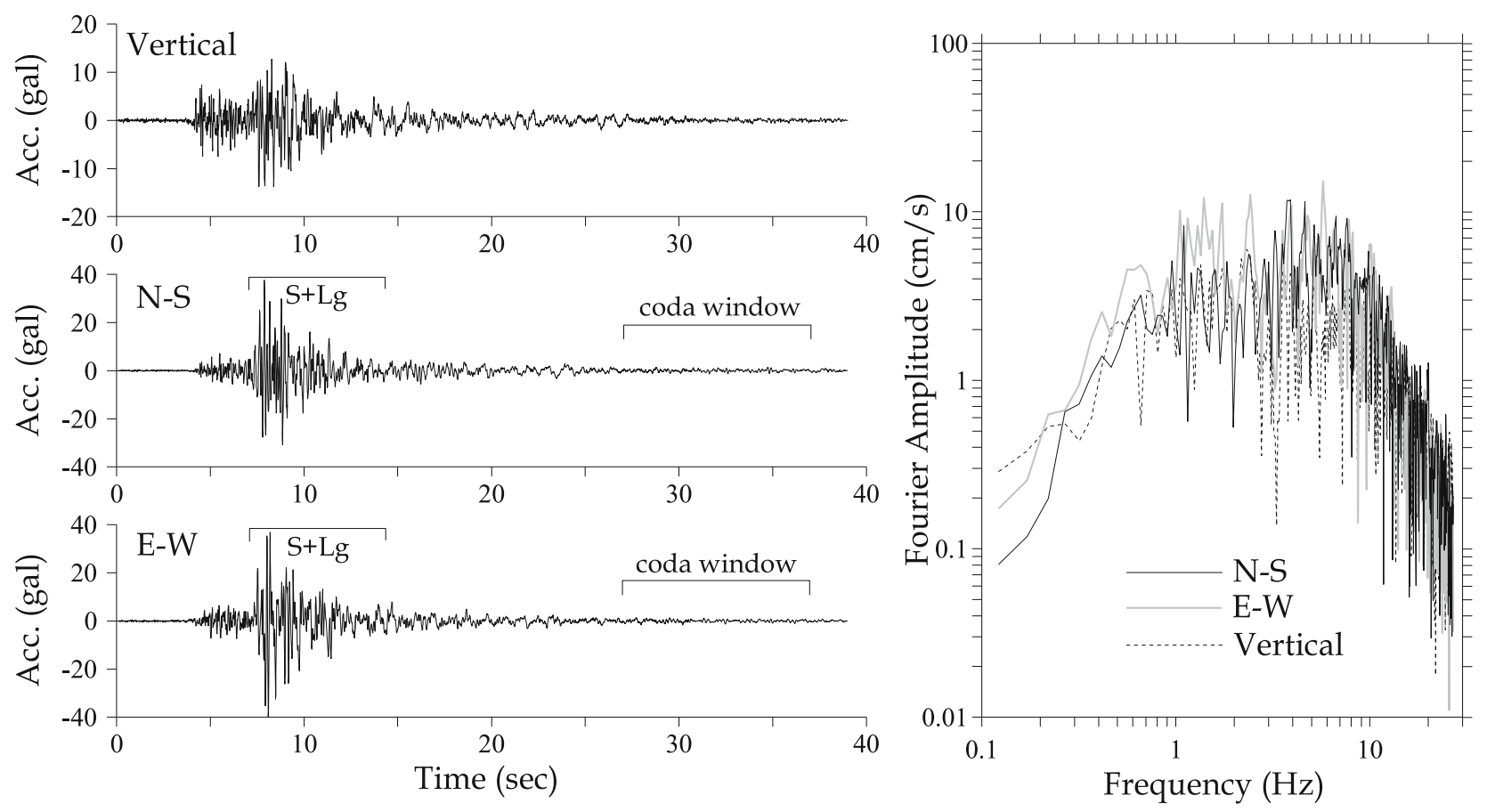

Fig. 3. An example of accelerograms and their corresponding Fourier amplitude spectra recorded at a reference station.

previous section, attenuation functions for the spectral acceleration at each frequency were estimated by choosing a reference hypocentral distance of $40 \mathrm{~km}$ to remove the effect due to the arbitrariness in the choice of the coda duration. The normalized amplitudes for frequencies are shown in Fig. 4. It is obvious that the peak motions measured at a larger distance present a relatively slower decay with hypocentral distance. In addition, the average amplitudes for distances larger than $100 \mathrm{~km}$ were not used to develop the attenuation functions described below due to possible mis-estimates from the incomplete coda waves.

The empirical anelastic attenuation function can be modeled using the following functional form (equation (13) in
Malagnini et al., 2000):

$$
\begin{aligned}
\log a_{\mathrm{cn}}\left(r, r_{\mathrm{ref}}, f\right)= & \log g(r)-\log g\left(r_{\mathrm{ref}}\right) \\
& -\frac{\pi f\left(r-r_{\mathrm{ref}}\right)}{\beta Q_{0}\left(f / f_{\mathrm{ref}}\right)^{\eta}} \log e,
\end{aligned}
$$

where $r$ is the hypocentral distance. $Q_{0}$ is the $Q s$ value at the reference frequency $f_{\text {ref }}$ of $1 \mathrm{~Hz}$ and $\eta$ is the frequencydependence factor. The reference hypocentral distance $r_{\text {ref }}$ used here is $40 \mathrm{~km}$ and the average shear-wave velocity $\beta$ in the source regions is supposed to be $3.5 \mathrm{~km} / \mathrm{s}$ according to the layered structure in Taiwan (Yeh and Tsai, 1981). $g(r)$ is a piecewise linear geometrical spreading function. Similarly to the multi-segment models assumed in Atkinson and 

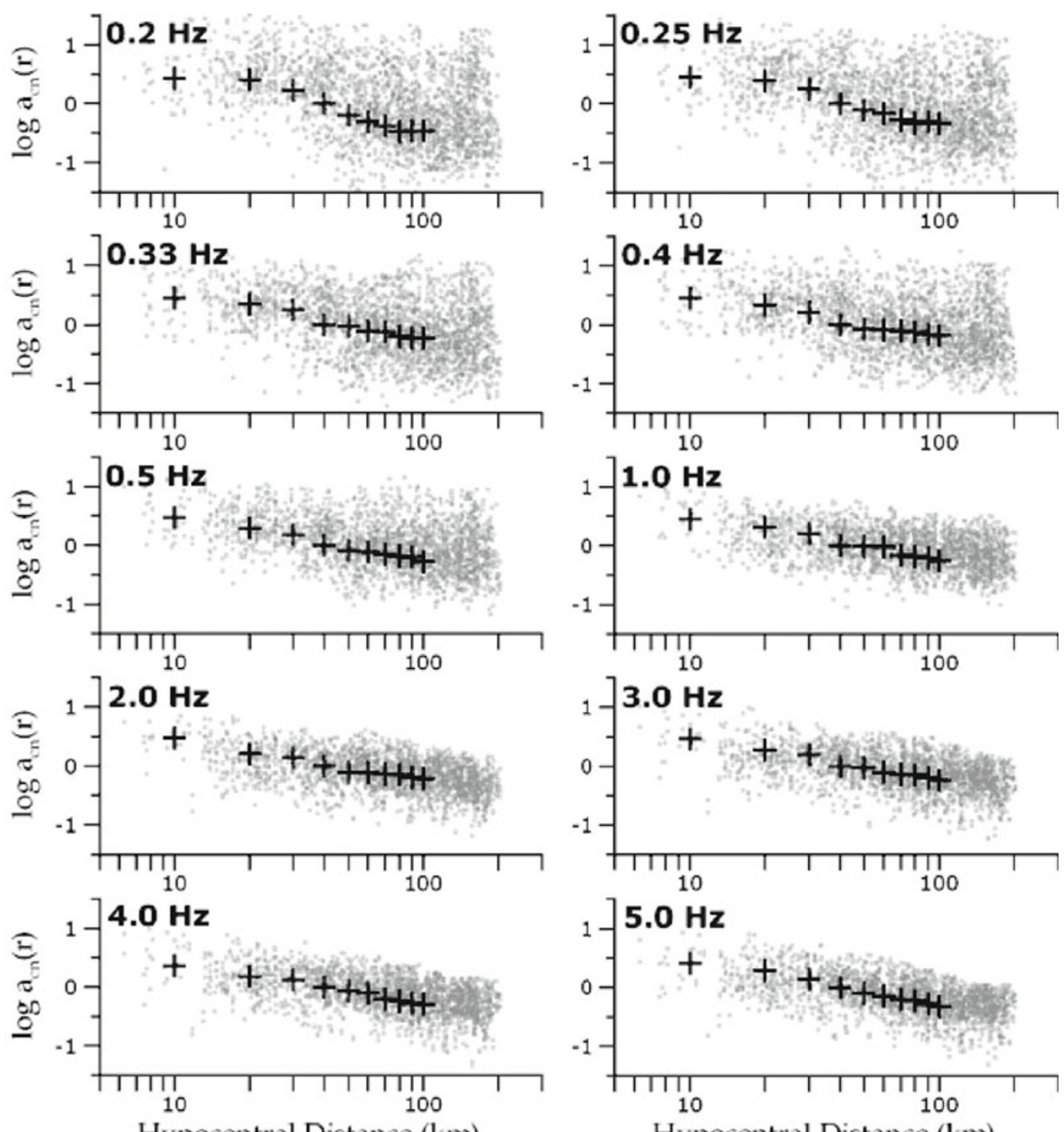

Hypocentral Distance $(\mathrm{km})$

Hypocentral Distance $(\mathrm{km})$

Fig. 4. Modeled attenuation curves of the normalized spectral accelerations at 10 different frequencies recorded at reference stations. The averages (crosses) were determined by the $\mathrm{L}_{1}$-norm minimization.

Mereu (1992) and Atkinson and Boore (1995), when considering dominant wave types at various distances, a bilinear geometrical spreading function was used herein. This is in the form $1 / r^{b}$, where $b=1.0$ for $r<50 \mathrm{~km}, b=0.0$ for $50 \leq r<200 \mathrm{~km}$. This model was used for the Taiwan region (Sokolov et al., 2000) and was also adopted by Roumelioti and Beresnev (2003), based on data averaging of a variety of site conditions from rock sites to soft soils of different thicknesses. From Eq. (4) and the assumed geometrical spreading function $g(r)$, the average $Q s$ values can be estimated by giving the distances and the coda-normalized amplitudes at frequencies. These discrete anelastic attenuation factors varying with frequency were fitted with the linear function shown in Fig. 5. Therefore, the frequencydependent $Q$ model generalized for the whole of Taiwan, as the input parameter of simulation using the random vibration theory, can be expressed as:

$$
\begin{aligned}
& Q(f)=100\left(f / f_{\text {ref }}\right)^{0.70}, \\
& f>0.2 \mathrm{~Hz}, \quad f_{\text {ref }}=1.0 \mathrm{~Hz} .
\end{aligned}
$$

The quality factor increases with a frequency-dependence exponent of about 0.70 , which is smaller than that derived only from reference stations between the Taipei basin and the Ilan plain for earthquakes in northeastern Taiwan (Chung, 2007). This discrepancy implies that the crustal structure in central and southern Taiwan could be more fractured than in northern Taiwan. Several previous studies (Wang, 1987; Chen, 1998; Chung et al., 2009) were reviewed and compared to outline variations in common. In general, there is no significant difference between their results and ours. However, the regionalization for the frequency-dependent $Q$ factor in the Taiwan area, as shown in Chung et al. (2009), is worth considering for modeling the attenuation function in the future.

\section{Peak Ground Motions at Reference Sites}

In this study, a stochastic method was used to simulate ground motion by building functional descriptions of the ground motion's amplitude with a random phase spectrum, as represented by Eq. (1). Then, by using the random 


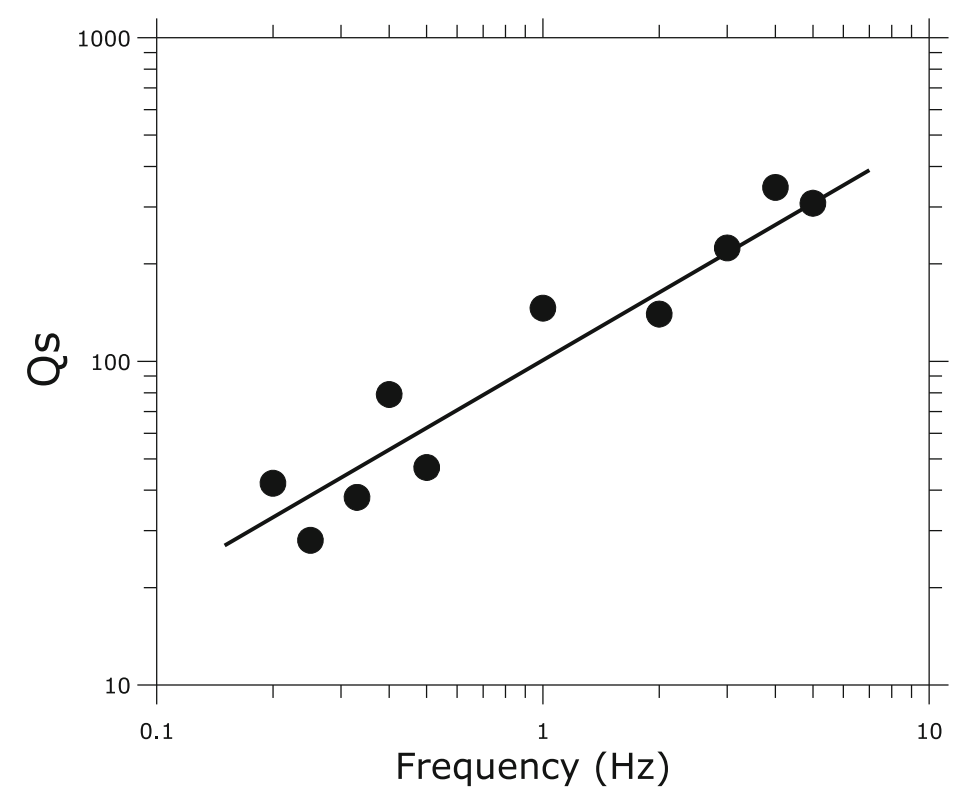

Fig. 5. Shear-wave $Q$ model (represented as the solid line) adopted in this study. The linear relationship was regressed from $Q$ values for the 10 frequencies of interest.

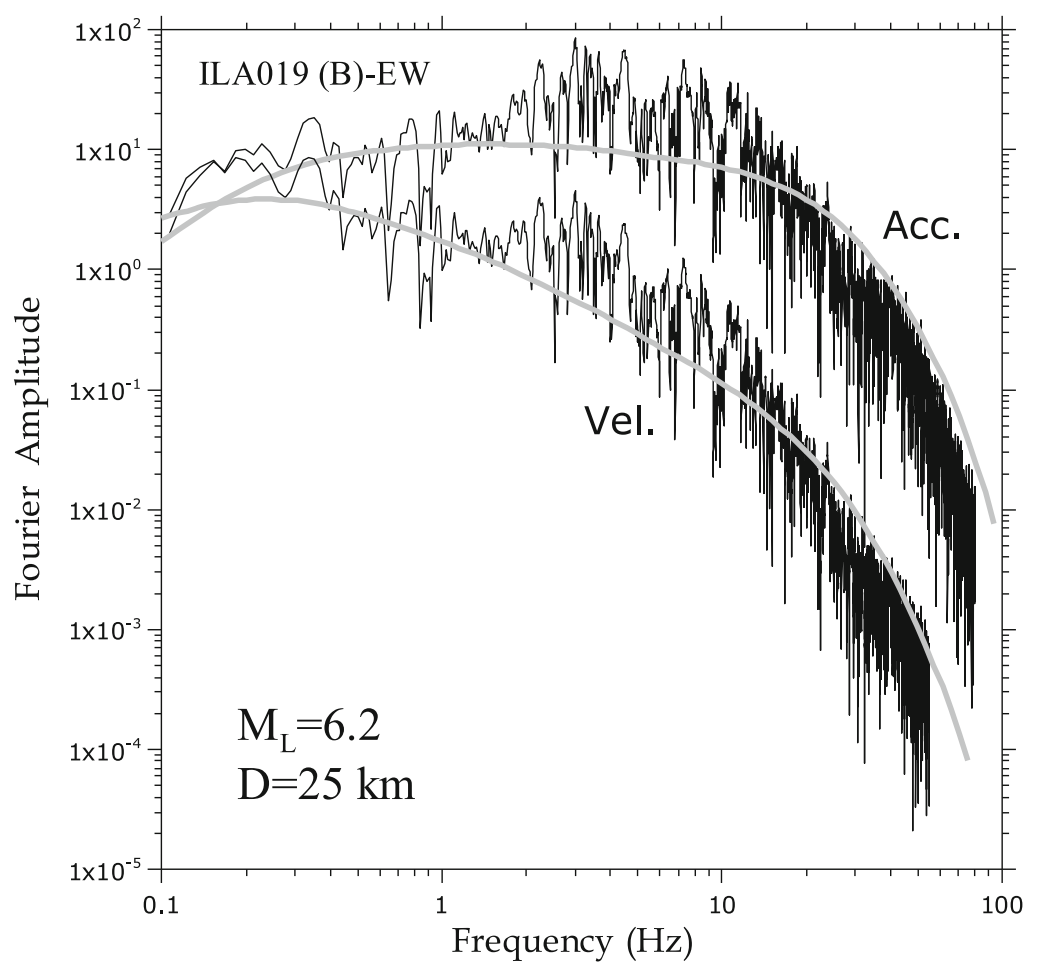

Fig. 6. Fourier amplitude spectra of the EW-component accelerogram and the integrated velocity time history modeled at a rock-based station. The recorded spectra (black curves) for a local magnitude of 6.2 and distance of $25 \mathrm{~km}$ were illustrated respectively for comparison.

vibration theory as initially proposed by Cartwright and Longuet-Higgins (1956), the extremes of transient earthquake ground motions could be obtained giving the Fourier amplitude spectra of the time history and signal duration. The essential aspects of this theory is described in Appendix A. A computer code (Boore, 2000) was therefore used in this study, which demands several input parameters including the seismic source spectrum, a crustal attenuation function and a distance-dependent duration function.

To model the path-independent loss of energy for ground motions at high frequencies, the spectral amplitudes predicted by source models have to be modified by multiplying a high-cut filter. A simplified diminution function $\exp \left(-\pi \kappa_{0} f\right)$, where $f$ is the frequency, representing the regional average of the combined effects for rock site amplification and anelastic attenuation in a mountain region, can therefore be introduced as a high-frequency attenuation operator to describe the exponential decay of the seismic spectrum (Anderson and Hough, 1984). The kappa values have been determined to be in the range $0.03 \sim 0.07 \mathrm{~s}$ for 

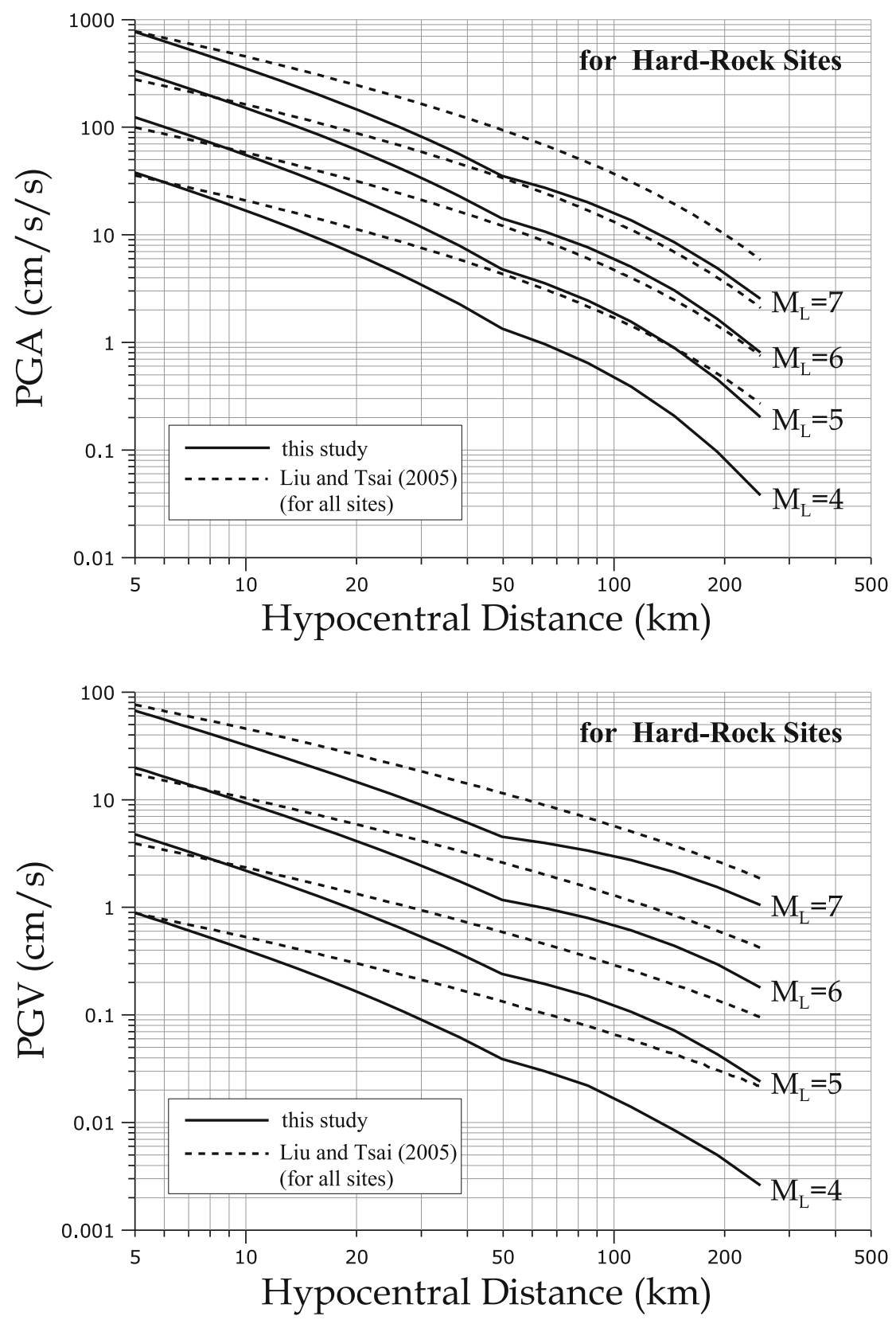

Fig. 7. Predictions of the peak horizontal ground acceleration (upper) and velocity (lower) as a function of hypocentral distance for a local magnitude ranging from 4 to 7 , respectively.

the generic site in Taiwan (Tsai and Chen, 2000). However, a fixed kappa value of $0.025 \mathrm{~s}$ was used in this study, after analyzing the records from reference stations. This value is similar to the one inferred from California ground motion records on rock sites (Boore et al., 1992). Instead of using the Haskell matrix method, the frequency-dependent amplifications relative to the source were calculated by the root-impedance approximation (see Boore, 2003, for details) outlined in Appendix B. It needs a layered velocity model and a density model referred to the shallow crustal structure in central Taiwan, which was proposed by Chen (1995) using a three-dimensional inversion of $P$ - and $S$ travel times from the CWB seismic network.

The duration of strong shaking is a function of the path, as well as the source duration that is related to the inverse of the corner frequency. The definition of the duration of ground motion in this study is given as the width of the time window that limits the $5 \% \sim 75 \%$ portion of seismic energy following $P$-wave arrival (Trifunac and Brady, 1975). Consequently, for our dataset, the duration increases gradually from $3.5 \mathrm{~s}$ for zero distance to $10.5 \mathrm{~s}$ at about $100 \mathrm{~km}$ of recording distance.

As regards the source spectrum in Eq. (1), the typical $\omega$-square model (Aki, 1967; Brune, 1970) with a singlecorner frequency was adopted in this study. The radiation coefficient averaged over some portion of the focal sphere is assumed to be 0.55 if the partition factor of the $S$-wave energy is taken to be $1 / \sqrt{2}$ (Boore and Boatwright, 1984). The stress drop of moderate seismic sources in the range from 10-100 bar was derived by Chiang (1994). For some moderate-to-large earthquakes, a wider range (3 180 bar) of stress drops was suggested through a waveform inversion 

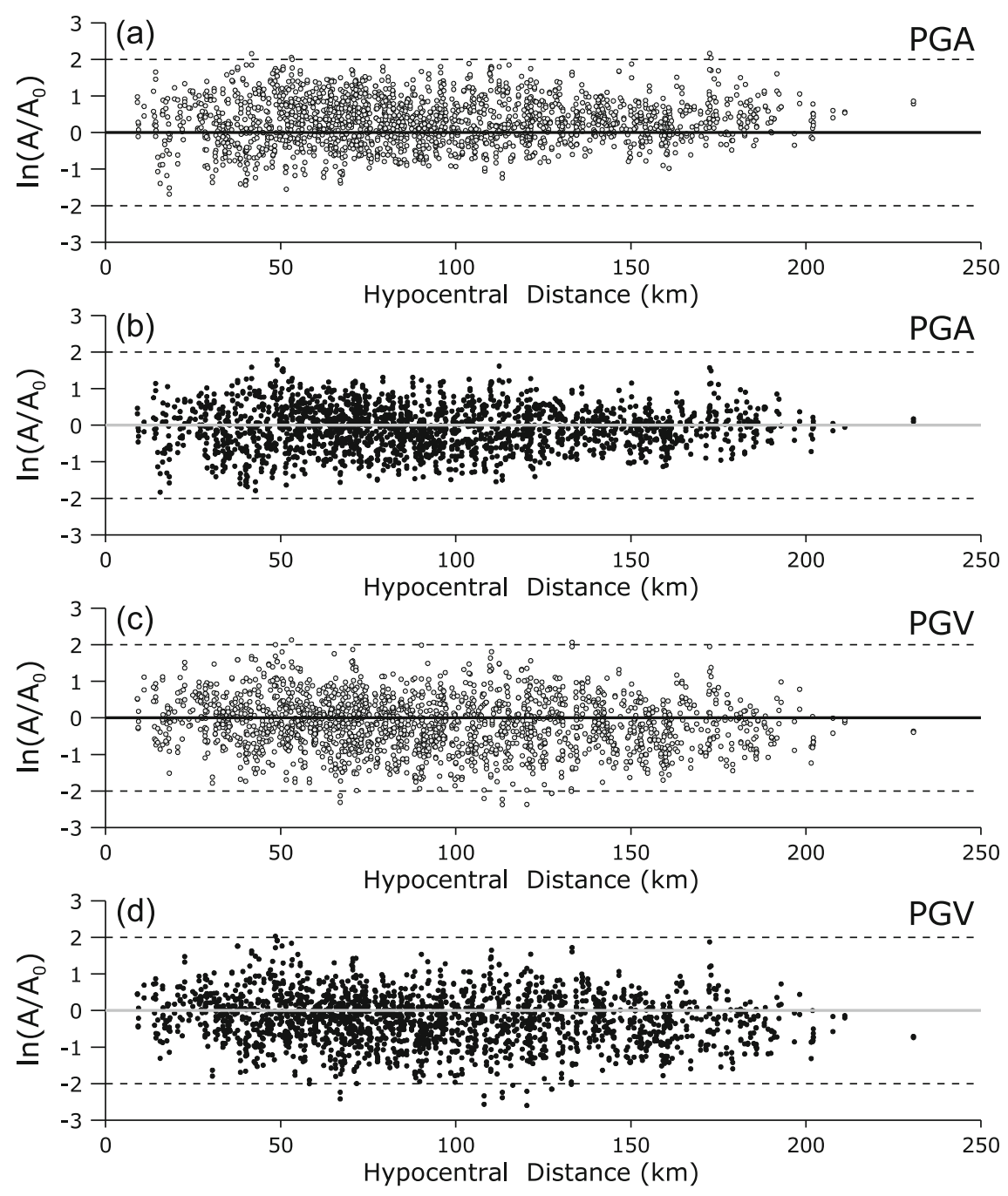

Fig. 8. Misfits between the observed peak values $(A)$ at reference stations and the predicted ones $\left(A_{0}\right)$ for (a) PGA and (c) PGV without the site-factor correction, and (b) PGA and (d) PGV with the site-factor correction, respectively.

analysis (Wu, 2000). In Wu's study, an average stress drop of 30 bar has been obtained, which was therefore chosen as the input parameter in the predictive model here.

The amplitude spectrum can, therefore, be modeled in the stochastic simulation, based on the empirical parameters associated with source characteristics and propagation behavior. Neglecting the usual site effects, for example, the modeled amplitude spectra for the magnitude and distance considered are shown in Fig. 6. Like most other cases, the predicted horizontal ground motion spectra at a reference site are generally comparable to those observed. Finally, using random vibration theory, with the inputs of empirical parameters as described in previous sections, and adopting an empirical equation for the magnitude conversion, $M_{\mathrm{W}}=0.99 M_{\mathrm{L}}+0.052(\mathrm{Wu}, 2000)$, the predictions of the peak horizontal ground motions (PGA and PGV) at the reference sites for local magnitudes $M_{\mathrm{L}}=4.0,5.0$, 6.0, and 7.0, respectively, are shown in Fig. 7. The change at a hypocentral distance of $50 \mathrm{~km}$ in these curves is attributed to the change at this distance defined in the bilinear geometrical spreading function. The predicted motions for shear waves, particularly at distances greater than 30 $\mathrm{km}$, are much lower than previous simulations which were based on the statistical regression of peak values taken from all the recordings made at generic stations (e.g., Chang et al., 2001; Liu and Tsai, 2005). It is to be expected that the differences would be reduced if only data from rock sites had been used in these studies, even for a different set of earthquakes. This shows that the site amplification effects on free-field ground could predominate in the predictions. In addition, the peak motions used in these studies were probably picked from surface waves generated from some very shallow major seismic sources. Readings not arising from shear waves cannot essentially be modeled by a general source spectrum as used here. In order to obtain recorded PGVs, the time histories of ground-particle velocity were derived, using integration in the frequency domain and a bandpass filtering of $0.1 \sim 20 \mathrm{~Hz}$, from recorded accelerograms. For evaluating the proposed model, the residual values, which are defined as the natural logarithm of the ratio of the observed value to that predicted, are illustrated as a function of the hypocentral distance (Figs. 8(a) and 8(c)). Their distribution patterns confirm that the parameters related to the attenuation behavior of seismic waves are appropriate in the prediction. 

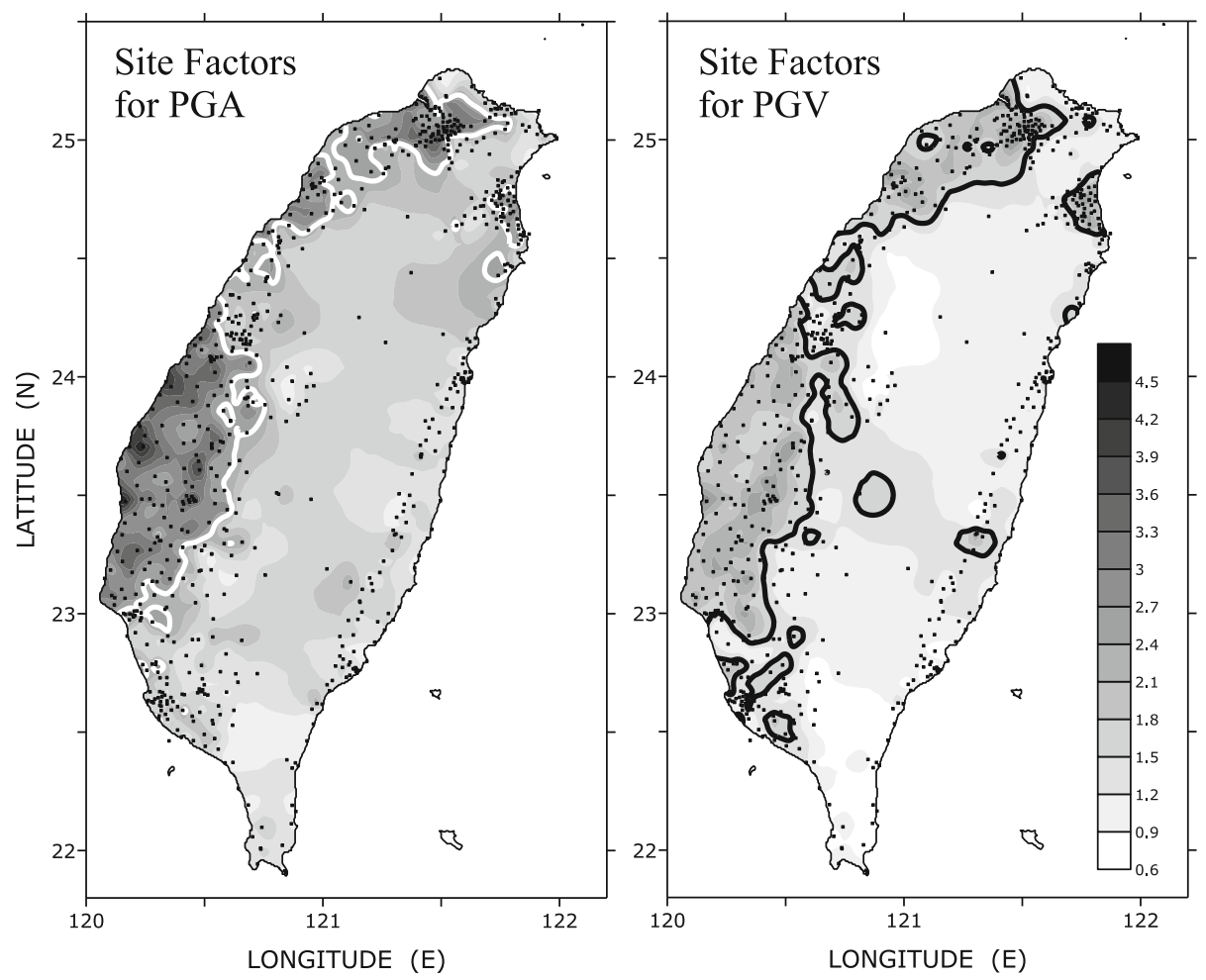

Fig. 9. Distribution of site factors for PGA and PGV shown by contours in an interval of 0.3 . The heavy lines indicate the contours of 2.4 for PGA and of 1.5 for PGV, respectively. The dots denote the 735 free-field strong motion stations analyzed in this study.

\section{Distribution of Site Factors}

With the advantage of island-wide deployment of freefield accelerometers under the 6-year instrumentation program conducted by the CWB since 1992, the amplification of seismic waves at each station due to soil subsurface layers can be obtained based on the number of observations and our prediction model shown in Fig. 7. In this study, the amplification of a seismic wave, strictly speaking, is defined by a relative factor depending on the reference derived from the empirical modeling, and can be properly called the site factor. It is defined as the average of the ratios of the observed peak value to that predicted for all used data. In addition, they are not linked to any particular ground motion frequency, because their calculation is made without considering the frequencies of PGA or PGV. By multiplying the predicted values by the corresponding site factors, therefore, the residuals reduce to a lower level with a zero mean (Figs. 8(b) and 8(d)).

In 54 shallow earthquakes with a local magnitude ranging from 5.0 to 7.0, a total number of 11,915 3-component accelerograms, which were recorded at 735 free-field stations (including 65 reference sites) of TSMN, are available to estimate the site factors. For $80 \%$ of stations, about 10 to 35 recordings can be collected to calculate the average site factor of each station by taking their arithmetic mean. Peak values of two horizontal components for each recording were here considered as two independent measurements. Consequently, empirical PGA and PGV site factors for all the stations were estimated, and are shown in contour maps (Fig. 9). Even though these calculations suggest that the surficial geology has a greater influence on ground motions than might be expected based on its site class alone, there are some scatters that probably depend on the earthquakes or the paths. For this reason, the widespread shallow moderate-to-large earthquakes in the Taiwan area are analyzed for the averaging of site factors. In general, these results for the soil sites suggest an amplification of $2.0 \sim 3.5$ for PGA and about $1.3 \sim 2.6$ for PGV, respectively when the reference motion is constrained. From the distribution maps, larger site factors can be remarked in the Taipei area, the Ilan plain, and regions along the coast in western Taiwan, where there are highly populated areas. The notable features in separating evident amplification from the overall distributions are highly related to the regions underlain by thick Quaternary sediments. However, the results also exhibit significant variations within these soft regions show that very local site conditions may dominate the ground motions in a complicated way. The other larger site factors appear in the northwestern coastal regions mostly underlain by stiff soil, which can also significantly amplify the ground motions in the high-frequency range.

The site factors estimated in the mountain regions, including the Longitudinal Valley, on the other hand, are in the range of 0.9 to 1.5 for PGA and 0.8 to 1.3 for PGV, respectively. It is obvious that constrained observations in the broad Central Range were limited at the reference sites, through a lack of information regarding the site response is not critical for hazard mitigation in such sparsely populated areas.

\section{Residual Analyses with Site-Factor Correction}

To evaluate the usability of empirical site factors on the prediction of peak ground motions, residual analyses for the earthquakes considered were implemented in this study. 


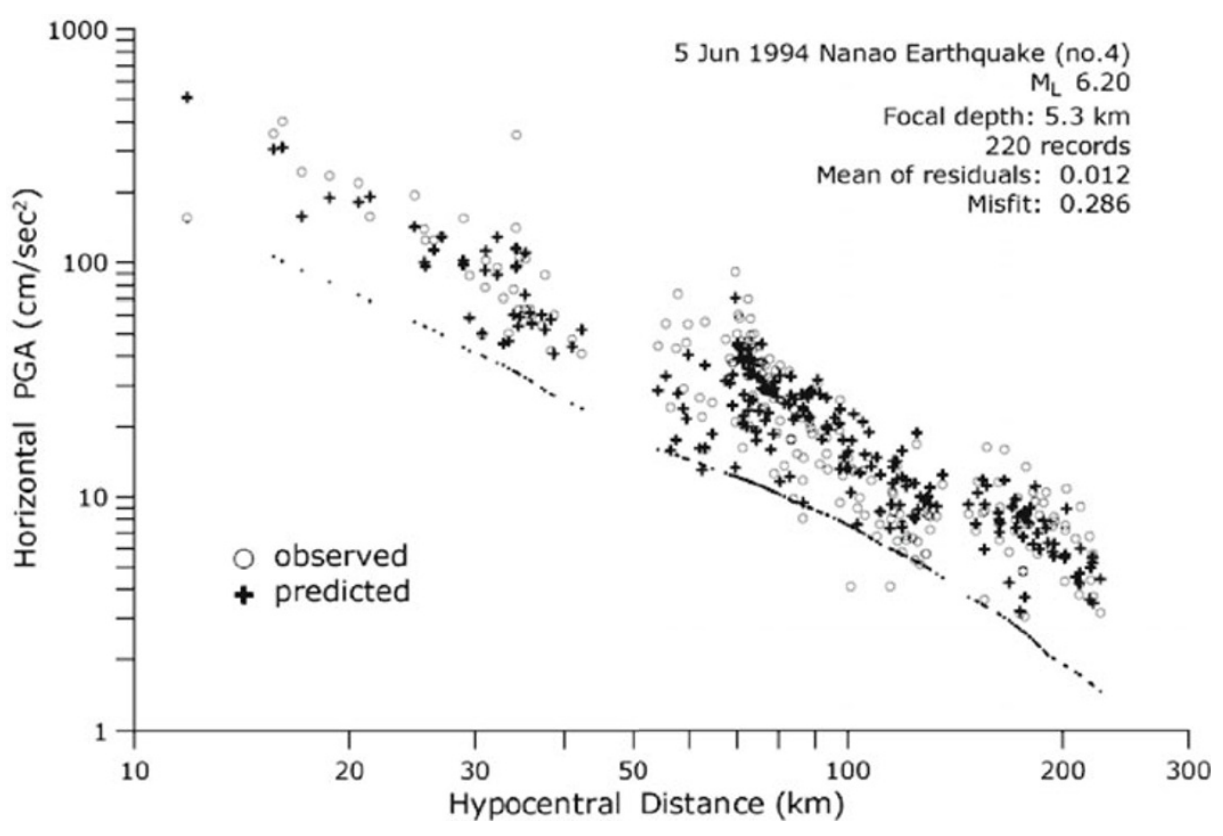

Fig. 10. Comparisons between the observed horizontal peak accelerations of shear waves and the predicted ones for the 1994 Nanao earthquake. Small dots along the hidden attenuation curve represent the PGAs derived from the reference model.

The residual is defined as the natural logarithm of the ratio of the observed peak value for a shear wave to that predicted and corrected by the site factor. On average, over 450 observations of horizontal components can be collected to perform an error distribution for each analyzed earthquake. A common used misfit ( $\operatorname{err}_{\mathrm{ln}}$ ) of a set of residuals can be defined as follows:

$$
\operatorname{err}_{\ln }=\sqrt{\sum_{i=1}^{N}\left(\ln A_{i}-\ln A_{0 i}\right)^{2} / N}
$$

where $N$ is the number of residuals for one earthquake. The geometrical mean of NS- and EW-component peak values $\left(A=\sqrt{A_{\mathrm{NS}} \times A_{\mathrm{EW}}}\right)$ was taken to compare with the predicted value $\left(A_{0}\right)$ for each record.

Figure 10 shows the comparative result of PGA for the 1994 Nanao earthquake, which had a magnitude of 6.20 on the Richter scale, located near the Ilan plain in northeastern Taiwan. Obviously, the misfit has been reduced to 0.286 when introducing the respective site factor at every station for modifying the prediction based on the reference model. According to the definition of Eq. (6), the value of the misfit cannot indicate the systematic deviation of residuals, which is one important factor to characterize the source terms of an individual earthquake. Therefore, the arithmetic average of a set of residuals for each event has to be calculated to evaluate the validity of the simulation. Consequently, the average residual of the predictions of PGA is 0.012 for the Nanao earthquake, which can be regarded as a good result. In other cases such as this example, the intensity maps can be recovered in the scenario simulation for seismic hazard assessment. The same comparison for PGV is also illustrated in Fig. 11 and reveals a good correspondence in a misfit of 0.263 with an average residual of 0.054 .

The expected consequence of residual analyses on an earthquake's dataset is that a relatively smaller PGA mis- fit range from 0.30 to 0.50 can be derived for most of the events. However, when reviewing the results, not every prediction of ground motion can be considered commendable as in the case of the Nanao earthquake. Some show large misfits even up to 1.10 , which are almost twice the values obtained from prediction equations based on the classical regression method without a site correction by Chang et al. (2001) and Liu and Tsai (2005). All the misfits for the earthquakes analyzed here are shown in Fig. 12, to highlight those showing poor agreement. For those events with a large misfit, the remarkable figures on the residuals consistently describe a systematic bias spread over a wide range of recording distance, but simultaneously show a regular dispersion from the average compared to the rest with a small misfit. Such a pattern of residual distribution can adequately state a high reliability in adopting the reference prediction models. The most likely causes, therefore, come from relevant factors of the seismic source, including the stress drop and the magnitude. The Richter magnitudes of the events considered were not recalculated in this study. It is accordingly difficult to evaluate the influence of a mis-estimate of $0.1 \sim 0.2$ in magnitude. An average stress drop of 30 bar was specified as an input parameter in the predictive model. As indicated from previous investigations (Ou and Tsai, 1993; Huang et al., 1996; Huang and Yeh, 1999; Wu, 2000; Huang et al., 2002), the variation in the estimation of the stress drop for earthquakes in different regions of Taiwan might be large enough to result in a significant bias in the ground motion prediction. These potential sources of error will be unavoidable when using a general source model with fixed parameters. However, about $80 \%$ of the earthquakes analyzed are well constrained in PGA predictions by an average misfit of less than 0.60 . The overall PGA misfit is 0.49 for all 54 events, which is much lower than values $(0.60 \sim 0.70)$ derived in other studies using statistical regression analyses. For PGV predictions, about $75 \%$ of 


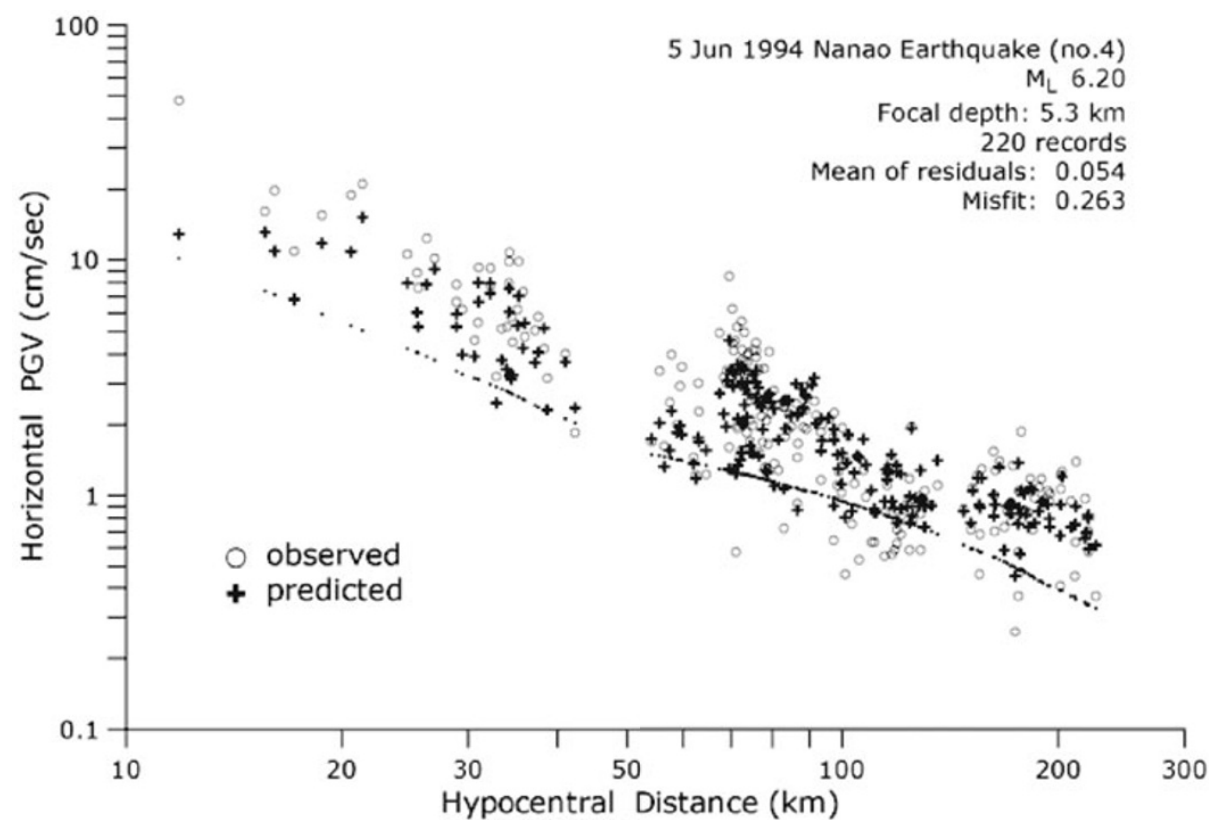

Fig. 11. Comparisons between the observed horizontal peak velocities of shear waves and the predicted ones for the 1994 Nanao earthquake. Small dots along the hidden attenuation curve represent the PGVs derived from the reference model.

(a)
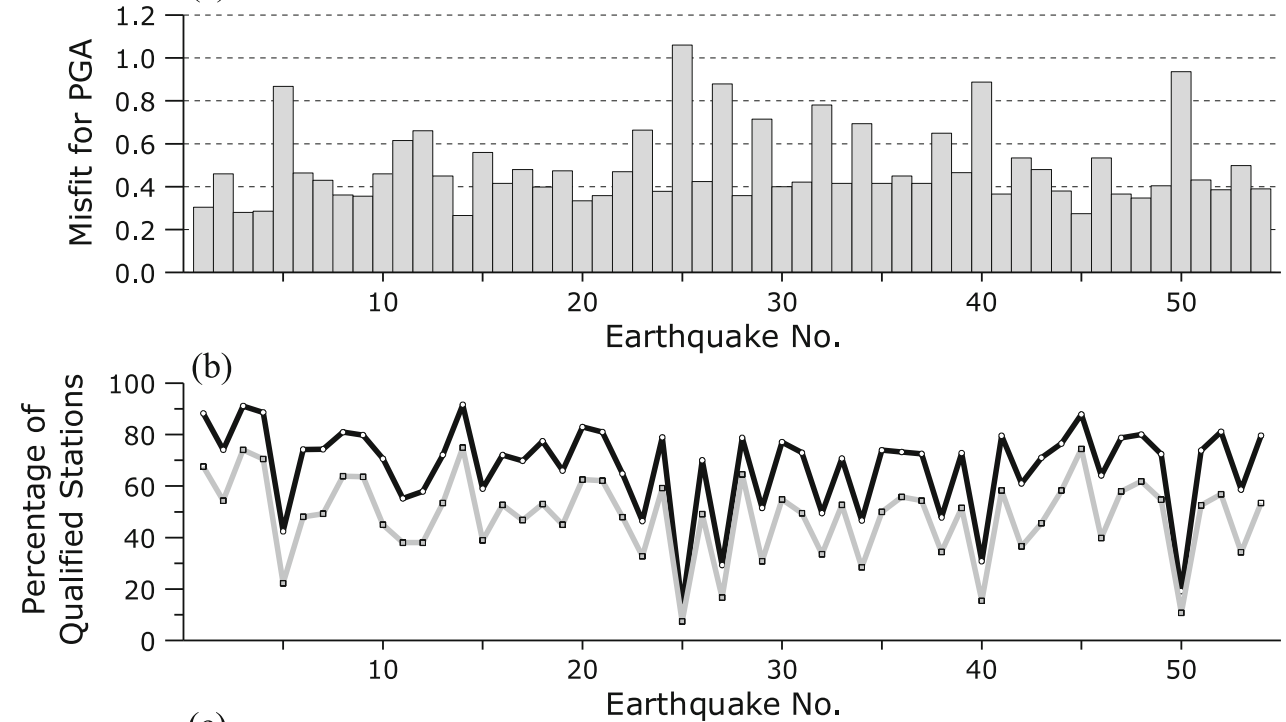

(c)

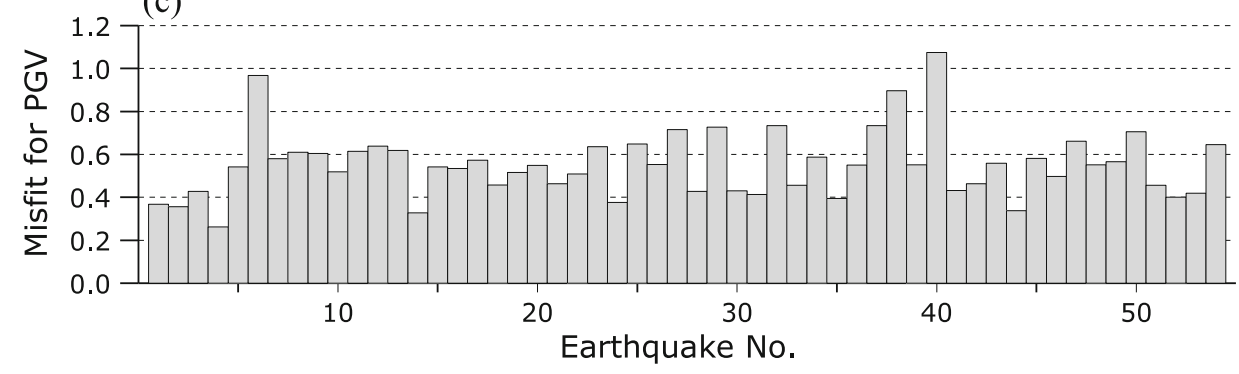

Fig. 12. Misfits of prediction residuals of (a) PGA and (c) PGV for the 54 analyzed earthquakes. Each vertical bar indicates the average misfit of the prediction for the corresponding earthquake labeled with the number listed in Table 1 . The percentages of qualified stations are denoted by a black line in (b) for $R_{0.57}$ and by a gray line for $R_{0.38}$, respectively.

events reveal an average individual misfit of less than 0.60 , with an overall misfit of 0.58 .

Seismic intensity at local areas is undoubtedly the information of most concern for the public. Another way to evaluate the reliability of peak ground motions predicted here is to take count of recording stations, whose seismic intensities can be exactly predicted, for determining the performance rate in the dissemination of intensity in- 
Isoseismal Maps of 22 Oct 1999 Chiayi Earthquake (no.20)

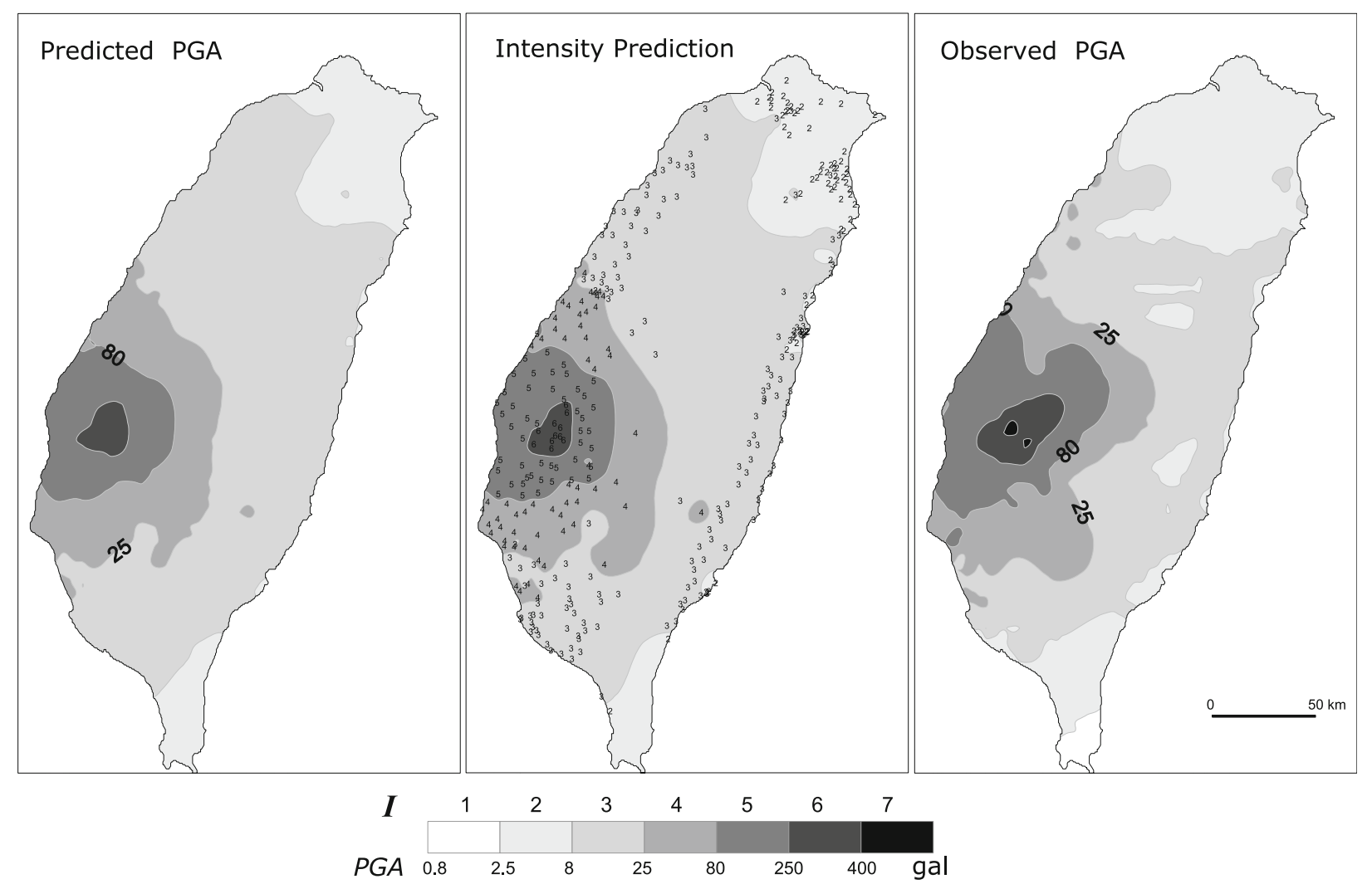

Fig. 13. Comparison of isoseismal maps contoured using predicted PGA values (left), observed PGA values (right), and predicted intensity values (middle), respectively.

formation. In the CWB's intensity scale, a seismic intensity $(I)$ of under 7 was defined by the relationship (Hsu, $1979), \log A_{I}=(I / 2)-0.6$, which approximately correlated with the threshold of peak ground acceleration $\left(A_{I}\right)$ in gals recorded by the accelerograph. Additionally, PGAs larger than 400 Gals were categorized into intensity 7. From a statistical viewpoint, a probability between $50 \%$ to $100 \%$ of a correct intensity prediction could be expected based on the assumption that the PGA residuals have an equal probability of appearance within the considered error ranges. For example, even for a PGA residual close to zero, only a slightly larger probability than $50 \%$ could be expected to obtain the correct intensity using the predicted PGA, when the observed PGA is just the threshold value crossing two consecutive intensity values, say $80 \mathrm{Gals}$, that defines the boundary between intensity 4 and 5 . If the observed PGA, say 140 Gals (classified to intensity 5, whose PGA ranges from 80 gals to 250 gals), is in the middle of two adjacent threshold values of intensity classification, however, up to a probability of $100 \%$ could be expected as long as the PGA residual is small enough. It is thus clear that the probability of a correct intensity prediction obviously depends both on the observed PGA and the prediction residual.

Therefore, on average, there will be at least a $75 \%$ probability of an exact intensity when the PGA residual can be reduced to half of the natural logarithm of the ratio of two PGA thresholds for consecutive intensity values, and about an $83 \%$ probability in the case of a residual smaller than one third of that range. Two qualified residuals, $R_{0.57}$ and
$R_{0.38}$, were therefore proposed in this study to evaluate the intensity predictions as follows:

$$
\begin{aligned}
& R_{0.57}=\frac{1}{2} \ln \left(\frac{A_{I+1}}{A_{I}}\right)=0.57 \\
& R_{0.38}=\frac{1}{3} \ln \left(\frac{A_{I+1}}{A_{I}}\right)=0.38
\end{aligned}
$$

where the intensity $I$ ranges from 1 to 5 . A reliable intensity map for the observed area can objectively be obtained when all the PGA residuals are smaller than the qualified ones. In practice, either qualified residual can be used as a reference to assess the results of intensity prediction. That is totally a probabilistic subject. In this study, the percentages of qualified stations, whose absolute values of the residual of peak accelerations are smaller than the qualified residuals, are shown in Fig. 12(b). Neglecting the data from a few earthquakes having a misfit larger than 0.65 , the average percentages of qualified stations for peak acceleration residuals less than $R_{0.57}$ and $R_{0.38}$ can attain $(75 \pm 8) \%$ and $(54 \pm 10) \%$, respectively, for most events. Such a performance would be good enough to produce a faithful intensity map for a moderate scenario earthquake in the Taiwan region. An example is shown in Fig. 13. For the 1999 Chiayi earthquake $\left(M_{\mathrm{L}}=6.40\right)$, PGA residuals smaller than $R_{0.57}$ were obtained at 282 stations (about $83 \%$ of a total of 340 triggered stations). In those qualified stations, 217 correct intensity predictions were performed which is $77 \%$. Due to the high percentage of qualified stations, the isoseismal map derived from predicted PGA values is very similar to 
that contoured using observed PGA values.

\section{Discussion and Conclusions}

Strong motion prediction is an important objective of seismic hazard assessment, particularly in the Taiwan region. As shown in previous historical data, however, peak earthquake ground motions can vary over a large range due to significant effects in terms of source, path, and site. Taking into account the advantage of flexibility in establishing a model for simulation, a stochastic method, which has been verified to be efficient, has been applied in this study to estimate the peak ground motion parameters of random time histories. Moreover, parameter analyses concerned with spectral amplitude, if necessary, can be carried out resulting in a greater understanding of ground motion.

First of all, for constructing a functional spectrum of ground motion, the generalized frequency-dependent $Q$ model (Eq. (5)), for describing the anelastic attenuation of seismic waves with distance for the crust in Taiwan, has been obtained using a coda normalization method. It is basically in good agreement with that proposed by Chung et al. (2009). Although the coda $Q$ from their investigation appears to be strongly dependent on the geology and tectonic features, it is still ambiguous as to how the spatial variations of the $Q$ value act on the amplitude and frequency content of seismic waves propagating through different materials. Such a problem related to path behavior would be very time-consuming to resolve in detail even if we knew how to achieve this. In the current stage, an averaged $Q$ model is reasonably satisfactory when applied for the rapid publishing of a preliminary map of strong shaking.

Secondly, the derived prediction models show acceptable results regarding the estimation of peak ground motions for shear waves at selected rock sites. Small biases relative to reference values may also be well corrected by empirical site factors for reducing the residuals to a generally lower level compared with previous results (e.g., Liu and Tsai, 2005). Some reference stations, however, exhibit a larger amplification in ground motion, probably due to the weathering condition of surface rock or near-site path effects characterized by a kappa value much smaller than 0.025 used in the model. For those known anomalous sites situated on hard ground or soft alluvium, more detailed investigations are necessary to determine their local area anomaly.

Based on reference ground motions, the site factors in mountain regions, including the Longitudinal Valley, are in the ranges 0.9 to 1.5 for PGA and 0.8 to 1.3 for PGV. The amplification factors expectably increase to about $2.0 \sim 3.5$ for PGA, and $1.3 \sim 2.6$ for PGV, at soil sites located in the Taipei area, the Ilan plain, and western coastal regions having large populations. Using these factors for modifying the predictions, a relatively smaller misfit range from 0.30 to 0.50 can be determined for most of the 54 analyzed shallow earthquakes. These results basically indicate that a preliminary isoseismal map for rapid reporting could be produced by the procedures implemented in this study. However, a large misfit, having an obvious systematic deviation of ground motion, can be shown in the predictions for some of the events. The possible reason causing such a type of residual pattern might be attributed to the stress drop of a seismic source which could be very different from the value of 30 bar used in this model. It appears to be difficult to determine the stress drop in a short time for simulating a better prediction of ground motion for the purpose of the rapid publication of the assessment of ground shaking hazards.

The proposed predictive model is reliable for moderate earthquakes $\left(M_{\mathrm{L}}<7\right)$ with a point source mechanism. However, two major uncertainties of peak ground motion prediction arise from the presence of strong surface waves, as well as a large earthquake with an extended rupturing source. This apparently implies that distant, or very shallow, earthquakes which can usually excite strong surface waves dominated by energy of a relatively low frequency must both be of large magnitude and long fault rupturing (Chung, 1995; Chung and Yeh, 1997; Chang et al., 2002). Such problems, therefore, are certainly subjects to be considered in the next stage of investigations relating to ground motion predictions.

Acknowledgments. I would like to thank Dr. C.-H. Chang of the Central Weather Bureau of Taiwan for archiving the accelerograms used in this study. This article has been considerably improved from its original form as a result of insightful reviews by two anonymous reviewers. Simulation of the ground motion was carried out using the SMSIM program ver. 2.18 written by Dr. D. M. Boore of U.S. Geol. Surv., which is available at his website http://www.daveboore.com/software_online.htm (last accessed July 2005). This research was primarily supported by the National Science Council, Taiwan, under the grants NSC 97-2745M-231-001 and NSC 98-2119-M-231-002. I would also like to acknowledge the support of the Central Weather Bureau via Grant MOTC-CWB-98-E-09.

\section{Appendix A. The Random Vibration Theory}

According to the equation from Cartwright and LonguetHiggins (1956) for the ratio of peak to rms motion, an improved equation for the extrema of transient earthquake ground motions with a random character was proposed by Boore (2003) as follows:

$$
\frac{y_{\max }}{y_{\mathrm{rms}}}=2 \int_{0}^{\infty}\left(1-\left(1-\xi \exp \left(-z^{2}\right)\right)^{N_{e}}\right) d z,
$$

where

$$
\xi=\frac{N_{z}}{N_{e}}
$$

and $N_{z}, N_{e}$ are the number of zero crossings and extrema, respectively, which are proportional to the frequency and the duration. The frequencies of zero crossings and extrema can be related to the moments $m_{k}$ of the squared spectral amplitude, which are defined as:

$$
m_{k}=2 \int_{0}^{\infty}(2 \pi f)^{k}|Y(f)|^{2} d f, \quad k=0,2,4,
$$

where $Y(f)$ is the spectrum corresponding to the seismological model given by Eq. (1).

\section{Appendix B. The Root-Impedance Approximation}

Boore (2003) has described how to convert a velocity and density model into approximate site amplifications using the square root of the impedance ratio between the source 
and the surface. The amplification, which is a function of frequency, can be expressed as:

$$
A(f)=\sqrt{Z_{S} / \bar{Z}(f)},
$$

where $Z_{S}$ is the seismic impedance near the source and $\bar{Z}(f)$ is a time-weighted average of the near-surface seismic impedance. Basically, the square-root impedance amplification is a first-order approximation of the total amplification derived by wave-calculation solutions.

\section{References}

Aki, K., Scaling law of seismic spectrum, J. Geophys. Res., 72, 1217-1231, 1967.

Aki, K., Attenuation of shear waves in the lithosphere for frequencies from 0.05 to $25 \mathrm{~Hz}$, Phys. Earth Planet. Inter., 21, 50-60, 1980.

Anderson, J. G. and S. E. Hough, A model for the shape of the Fourier amplitude spectrum of acceleration at high frequencies, Bull. Seismol. Soc. Am., 74, 1969-1993, 1984.

Atkinson, G. M. and D. Boore, New ground motion relations for eastern North America, Bull. Seismol. Soc. Am., 85, 17-30, 1995.

Atkinson, G. M. and R. Mereu, The shape of ground motion attenuation curves in southeastern Canada, Bull. Seismol. Soc. Am., 82, 2014-2031, 1992.

Boore, D. M., Stochastic simulation of high-frequency ground motions based on seismological models of the radiated spectra, Bull. Seismol. Soc. Am., 73, 1865-1894, 1983.

Boore, D. M., SMSIM-Fortran programs for simulating ground motions from earthquakes: Version 2.0-A revision of OFR96-80-A, U.S. Geol. Surv. Open-File Report. 96-80-A, 2000.

Boore, D. M., Comparisons of ground motions from the 1999 Chi-Chi earthquake with empirical predictions largely based on data from California, Bull. Seismol. Soc. Am., 91, 1212-1217, 2001.

Boore, D. M., Simulation of ground motion using the stochastic method, Pure Appl. Geophys., 160, 635-676, 2003.

Boore, D. M. and J. Boatwright, Average body-wave radiation coefficients, Bull. Seismol. Soc. Am., 74, 1615-1621, 1984.

Boore, D. M., W. Joyner, and L. Wennerberg, Fitting the stochastic omegasquared source model to observed response spectra in western North America: trade-offs between stress drop and kappa, Bull. Seismol. Soc. Am., 82, 1956-1963, 1992.

Brune, J. N., Tectonics stress and the spectra of seismic shear waves from earthquakes, J. Geophys. Res., 75, 4997-5009, 1970.

Cartwright, D. E. and M. S. Longuet-Higgins, The statistical distribution of the maxima of a random function, Proc. R. Soc. Lond., A237, 212-232, 1956.

Chang, T. M., K. L. Wen, T. Furumura, and H. J. Chiang, Surface wave excitation in the western coastal plain of Taiwan during the 1999 ChiChi earthquake, J. Chin. Inst. Eng., 25, 461-467, 2002.

Chang, T. Y., F. Cotton, and J. Angelier, Seismic attenuation and peak ground acceleration in Taiwan, Bull. Seismol. Soc. Am., 91, 1229-1246, 2001.

Chen, K. J., S-wave attenuation structure in the Taiwan area and its correlation to seismicity, Terr. Atmos. Ocean. Sci., 9, 97-118, 1998.

Chen, Y. L., Three dimensional velocity structure and kinematic analysis in Taiwan area, Master Dissertation of National Central Univ., Taiwan, 172 pp., 1995.

Chiang, C. H., Source scaling model in Taiwan area, Master Dissertation of National Central Univ., Taiwan, 77 pp., 1994.

Chung, J. K., Source Effects on the Generation of Short-period Surface Waves by Finite Element Method, PhD Dissertation of National Central Univ., Taiwan, 151 pp., 1995.

Chung, J. K., Estimation of ground strain using accelerograms recorded by two dense seismic arrays at Lotung, Taiwan, Terr. Atmos. Ocean. Sci., 18, 715-737, 2007.

Chung, J. K. and Y. T. Yeh, Shallow crustal structure from short-period Rayleigh-wave dispersion data in southwestern Taiwan, Bull. Seismol. Soc. Am., 87, 370-382, 1997.

Chung, J. K., Y. L. Chen, and T. C. Shin, Spatial distribution of coda Q estimated from local earthquakes in Taiwan area, Earth Planets Space, 61, 1077-1088, 2009.

Frankel, A., A. McGarr, J. Bicknell, J. Mori, L. Seeber, and E. Cranswick, Attenuation of high-frequency shear waves in the crust: Measurements from New York State, South Africa, and Southern California, J. Geophys. Res., 95, 17441-17457, 1990.

Hsu, M. T., Seismology, 388 pp., Liming Cultural Inc., 1979 (in Chinese). Huang, B. S., K. C. Chen, and Y. T. Yeh, Source parameters of the December 15, 1993 Tapu earthquake from first P- motions and waveforms, $J$. Geol. Soc. China, 39, 235-250, 1996.

Huang, M. W., J. H. Wang, R. D. Hwang, and K. C. Chen, Estimates of source parameters of two large aftershocks of 1999 Chi-Chi, Taiwan, earthquake in the Chia-Yi area, Terr. Atmos. Ocean. Sci., 13, 299-312, 2002.

Huang, W. G. and Y. T. Yeh, Characteristics of seismic source spectra from the Chai-Yi and Tai-Nan area of Taiwan, Terr. Atmos. Ocean. Sci., 10, 415-446, 1999.

Lee, C. T. and B. R. Tsai, Mapping Vs30 in Taiwan, Terr. Atmos. Ocean. Sci., 19, 671-682, 2008.

Lee, C. T., C. T. Cheng, C. W. Liao, and Y. B. Tsai, Site classification of Taiwan free-field strong-motion program, Bull. Seismol. Soc. Am., 91, 1283-1297, 2001

Lee, W. H. K., T. C. Shin, K. W. Kuo, and K. C. Chen, CWB FreeField Strong-Motion Data from the 921 Chi-Chi Earthquake, Digital acceleration files on CD-ROM, Seismology Center, Central Weather Bureau, Taipei, Taiwan, Volume 1, 1999.

Liu, K. S., Attenuation relations for strong seismic ground motion in Taiwan, PhD Dissertation of National Central Univ., Taiwan, 1999.

Liu, K. S. and Y. B. Tsai, Attenuation relationships of peak ground acceleration and velocity for crustal earthquakes in Taiwan, Bull. Seismol. Soc. Am., 95, 1045-1058, 2005.

Malagnini, L. and R. B. Herrmann, Ground-motion scaling in the region of the 1997 Umbria-Marche earthquake (Italy), Bull. Seismol. Soc. Am., 90, 1041-1051, 2000.

Malagnini, L., R. B. Herrmann, and M. D. Bona, Ground-motion scaling in the Apennines (Italy), Bull. Seismol. Soc. Am., 90, 1062-1081, 2000.

Ni, S. D. and H. C. Chiu, Stochastic modeling on the attenuation of peak ground acceleration in Taiwan, Proc. of the 3rd Taiwan Sympo. on Geophysics, Chung-Li, Taiwan, 95-105, 1991.

Ou, G. B. and S. F. Tsai, The estimation of ground motion in southwestern Taiwan: A study of ML-MW relation, National Science Council Report, Taiwan, 57 pp., 1993.

Raoof, M., R. B. Herrmann, and L. Malagnini, Attenuation and excitation of three-component ground motion in Southern California, Bull. Seismol. Soc. Am., 89, 888-902, 1999.

Rautian, T. G. and V. I. Khalturin, The use of the coda for determination of the earthquake source spectrum, Bull. Seismol. Soc. Am., 68, 923-948, 1978.

Roumelioti, Z. and I. A. Beresnev, Stochastic finite-fault modeling of ground motions from the 1999 Chi-Chi, Taiwan, earthquake: Application to rock and soil sites with implications for nonlinear site response, Bull. Seismol. Soc. Am., 93, 1691-1702, 2003.

Shin, T. C., Taiwan strong motion instrumentation program, Sympo. on Taiwan Strong Motion Instrumentation Program, Taipei, 1-10, 1993.

Shin, T. C., A preliminary study of the earthquake early warning system in the Taiwan area, Meteorological Bull., 42, 118-134, 1998.

Shin, T. C. and T. L. Teng, An overview of the 1999 Chi-Chi, Taiwan, earthquake, Bull. Seismol. Soc. Am., 91, 895-913, 2001.

Shin, T. C., K. W. Kuo, W. H. K. Lee, T. L. Teng, and Y. B. Tsai, A preliminary report on the 1999 Chi-Chi (Taiwan) earthquake, Seismol. Res. Lett., 71, 24-30, 2000.

Sokolov, V., C. H. Loh, and K. L. Wen, Empirical model for estimating Fourier amplitude spectra of ground acceleration in Taiwan region, Earthq. Eng. Struct. Dyn., 29, 339-357, 2000.

Spudich, P. and T. Bostwick, Studies of the seismic coda using an earthquake cluster as a deeply buried seismograph array, J. Geophys. Res., 92, 10526-10546, 1987.

Steidl, J. H., A. G. Tumarkin, and R. J. Archuleta, What is a reference site?, Bull. Seismol. Soc. Am., 86, 1733-1748, 1996.

Tan, R. Y. and C. H. Loh, Guidelines of aseismic safety evaluation and retrofit for telecommunication and transportation systems, Report of Ministry of Transportation and Communications, Taiwan, 1996.

Trifunac, M. D. and A. G. Brady, A study on the duration of earthquake strong motion, Bull. Seismol. Soc. Am., 65, 581-626, 1975.

Tsai, C. C. and K. C. Chen, A model for the high-cut process of strongmotion accelerations in terms of distance, magnitude, and site condition: An example from the SMART1 array, Lotung, Taiwan, Bull. Seismol. Soc. Am., 90, 1535-1542, 2000.

Tsai, C. C., C. H. Loh, and Y. T. Yeh, Analysis of earthquake risk in Taiwan based on seismotectonic zones, Memor. Geol. Soc. China, 9, 413-446, 
1987.

Tsai, Y. B. and B. A. Bolt, An analysis of horizontal peak ground acceleration and velocity from SMART-1 array data, Bull. Inst. Earth Sci., Academic Sinica, 3, 105-126, 1983.

Yeh, Y. H. and Y. B. Tsai, Crustal structure of central Taiwan from inversion of P wave arrival times, Bull. Inst. Earth Sci., Academia Sinica, 1, 83-102, 1981.
Wang, C. Y., A comparative study of $\mathrm{P}$ and $\mathrm{Lg}$ waves in the Taiwan area, National Science Council Report No. 74-70, 128 pp., 1987.

Wu, H. Y., Source analysis of moderate to large earthquake in Taiwan, Master Dissertation of National Central Univ., Taiwan, 119 pp., 2000.

J.-K. Chung (e-mail: jkchung@uch.edu.tw) 